\title{
Relationship of Pain, Function and Quality of Life with Disease Grading among Patients with Knee Osteoarthritis
}

\author{
Rajbir Kaur Bahia', Sarah Quais ${ }^{2}$ and Ammar Suhail ${ }^{3 *}$ \\ 'Department of Physiotherapy, Lyallpur Khalsa College, Jalandhar - 144001, Punjab, India \\ ${ }^{2}$ New Hope Physiocare Physiotherapy Clinic, New Delhi - 110025, India \\ ${ }^{3}$ Department of Physiotherapy, Lovely Professional University, Phagwara - 144411, \\ Punjab, India; asuhail38@gmail.com
}

\begin{abstract}
Knee Osteoarthritis (KOA) is a global public health problem. The prevalence of KOA is on the rise leading to increased disease burden. Female and older adults have a higher risk of developing KOA. The diagnosis of KOA is usually based on specific clinical signs and symptoms or based on structural changes evident on radiographs. The clinical decision for management in these patients is based on X-ray grading. Recently there is a discussion on concordance between clinical and radiological findings in KAO patients. Therefore, it is necessary to identify a relationship between patient-reported findings and disease grading based on standard radiographs. This cross-sectional study recruited KAO patients from rural and urban parts of Phagwara and Jalandhar, Punjab, India. Participants were identified during medical and physiotherapy camps. Participants were included based on the American College of Rheumatology Criteria (ACR). Demographic characteristics, pain intensity, functional status, and Quality of Life (QOL) were assessed and documented. Disease grading was done based on presenting $\mathrm{X}$-rays using grading proposed by Kellgren and Lawrence. The association between these variables was analyzed using $\mathrm{R}$ software and reported. We also predicted disease grading using QOL metrics. 120 Participants' data were included in the final analysis. Findings suggest an association between demographic (age, height, weight and BMI) variables and disease grading. Pain, functional status, and QOL were found to be associated with disease grading. SF-Physical functioning and SF-General Health QOL metrics significantly predicted disease grading. The study's findings suggest that disease grading based on X-rays shows an association with the participants' clinical presentation.
\end{abstract}

Keywords: Disease Grading, Epidemiology, Osteoarthritis, Quality of Life, Radiography

\section{Introduction}

Osteoarthritis (OA) is the most widespread form of arthritis reported among older adults ${ }^{1,2}$. The health care costs and disease burden are on the rise in many countries and are predicted to increase further in the future ${ }^{3}$. The knee joint is the most common joint affected with OA equated with other joints ${ }^{4}$. The prevalence of Knee Osteoarthritis (KOA) has shown a remarkable increase from 2002 to $2020^{3,5}$. The global occurrence of Knee Osteoarthritis (KOA) is reported as $22 \%$ among individuals aged 40 and over ${ }^{5}$. There are remarkable variations in prevalence and incidence among different parts of the world ${ }^{1,3}$ incidence and years lived with disability (YLDs). Prevalence reported among Asians (19.2\%) is higher as compared with other continents ${ }^{5}$.

In the literature, different parameters and criteria are specified for the diagnosis of KOA. Kellgren and Lawrence (KL) described the diagnosis of KOA based on

${ }^{*}$ Author for correspondence 
the presence of structural changes on X-rays ${ }^{6}$. The clinical diagnosis of $\mathrm{OA}$ is based on diagnostic criteria defined by the American College of Rheumatology (ACR) criteria $^{7}$, European League Against Rheumatism (EULAR) ${ }^{8}$ or National Institute for Health and Care Excellence (NICE) guidelines. Imaging in KOA is used for two purposes: 1. To aid in the differential diagnosis when the clinical picture is doubtful and 2. To decide management strategies in patients with $\mathrm{KOA}^{10-13}$.

In KOA patients, various management strategies are recommended, like exercise, education, lifestyle modifications, medications and surger $y^{14,15}$. The clinical decision-making for selecting a management strategy depends on pain intensity, proof of structural damage, conservative treatment failure and impaired quality of life $^{16}$. There is a discussion on concordance between clinical and radiological findings in KOA patients ${ }^{5,17,18}$. Studies report variation in terms of the association between disease grading and clinical presentation of patients. Therefore, the present study aimed to analyze the association of disease grading with pain intensity, functional status, and Quality of Life (QOL). Additionally, we also predicted disease grading using QOL metrics.

\section{Methods}

\subsection{Study Design and Setting}

The study was cross-sectional based in Phagwara and Jalandhar, Punjab, India. We followed STROBE guidelines for conducting and reporting the findings.

\subsection{Participants}

We recruited participants through rural and urban camps organized for providing primary medical and physiotherapy care. We used convenient sampling technique. The selection criteria comprised of: 1.40 years or older, 2. Complaints of knee pain on most days of the past month, 3. Diagnosis of bilateral knee OA based on radiographic findings, 4 . Complains of knee pain while doing activities of daily living and 5. Presence of morning stiffness for $\geq 30$ minutes. We only included females in our study as we did not get enough bilateral OA male participants. Participants were excluded if they had any history of previous surgery of lower limbs, hip OA or they had a history of any severe medical conditions. Participants signed informed consent before final participation, which was voluntary. The dependent variables were only collected for the more painful knee. The study was approved by the Project Approval Committee (PAC) of Lovely Professional University, Phagwara, Punjab, India. The study's ethical principles were in concordance with the WMA Declaration of Helsinki (Ethical Principles for Medical Research Involving Human Subjects) ${ }^{19}$.

\subsection{Procedure}

Eligible participants were screened for basic demographic characteristics such as age, weight and height. The corresponding author had experience in assessing and managing KOA patients graded the $\mathrm{X}$-rays using the KL grading system. The other authors confirmed the grading and any differences were discussed and amended. The other dependent variables, pain, health status and QOL, were assessed using the NPRS, WOMAC index and SF-36 questionnaire. Association between disease grading and the studied variables were analyzed.

\subsection{Outcome Measures}

\subsubsection{Pain}

Pain intensity was measured using a Numeric Pain Rating Scale (NPRS). NPRS is an 11-point scale with scores from 0 to 10.0 indicates "no pain," and 10 means "worst pain imaginable." Participants rated their pain on NPRS during three different activities: Walking, maneuvering stairs and resting pain. NPRS have been extensively tested in diverse populations and have excellent psychometric properties $^{20}$.

\subsubsection{Western Ontario McMaster Scale (WOMAC)}

We used WOMAC to assess the health status of the individuals. WOMAC is a self-administered health status measure commonly used in patients with hip and KOA. WOMAC assesses three different domains affecting health (pain, stiffness and function) $)^{21,22}$. Higher scores on the scale suggest the low health status of the patients. WOMAC is available in two different formats, visual analog and Likert-boxes versions. We used a Likert version of the scale. WOMAC scores can be described in terms of percentages and total scores. We used total scores in the final analysis, did not categorize scores into different sections. The psychometric properties of the WOMAC scale are well studied and reported in the literature ${ }^{23}$. 


\subsubsection{Short Form-36}

SF-36 was used to assess the Quality of Life (QOL) in our study. SF-36 is the most used health-related quality of life measure utilized in research ${ }^{24}$. SF-36 is divided into eight different concepts of health (Table 1). The public version of SF-36 and its scoring instructions can be accessed from the RAND Corporation website. We calculated the scores for eight scales using the same instructions ${ }^{25}$. Higher scores on the scales indicate better QOL.

\subsection{Data Analysis}

The association of disease grading with the demographic characteristics, pain, health status and QOL were assessed using Kendall's tau. Since many different tests were conducted (one for each variable), we adjusted the p-values using the procedure of Benjaminij-Hochberg to arrive at the false discovery rates $(\mathrm{FDR})^{26}$. Logistic regression was calculated to assess whether any of the QOL metrics could predict disease grading. The data was analyzed using $\mathrm{R}$ software.

\section{Results}

A total of 120 participants were included in the study. The mean age of the sample was mean (SD) 59.79 (9.861). Demographic characteristics are mentioned in table 2. The data propose an association between demographic variables, pain, functional status, and quality of life metrics with disease grading (Table 3 ).

The association between the WOMAC Score and disease grading was positive and statistically significant ( b 0.5777, FDR 2.683e-15). Participants with the more

Table 1. SF-36 Scales and associated abbreviation used in the study ${ }^{27}$ Ware and Sherbournel published a new short-form health survey, the MOS 36-Item ShortForm Health Survey (SF-36)

\begin{tabular}{|l|}
\hline SF-36 Scales \\
\hline Physical Functioning (SF1) \\
\hline Role limitations due to physical health (SF2) \\
\hline Role limitations due to emotional problems (SF3) \\
\hline Energy/Fatigue (SF4) \\
\hline Emotional well-being (SF5) \\
\hline Social Functioning (SF6) \\
\hline Pain (SF7) \\
\hline General Health (SF8) \\
\hline
\end{tabular}

Table 2. Baseline demographic characteristics $(\mathrm{N}=120)$

\begin{tabular}{|l|l|}
\hline Variables & Mean \pm SD \\
\hline Age & $59.79 \pm 9.861$ \\
\hline Weight & $69.558 \quad \pm 10.774$ \\
\hline Height & $160.42 \pm 8.208$ \\
\hline BMI & $27.036 \pm 3.825$ \\
\hline NPRS & $5.89 \pm 2.199$ \\
\hline WOMAC & $57.6 \pm 14.86$ \\
\hline
\end{tabular}

Abbreviations: SD: Standard Deviation, BMI: Body Mass Index, NPRS: Numeric Pain Rating Scale, WOMAC: Western Ontario McMaster Scale

advanced disease tend to have a higher WOMAC rating score. For SF-36 scales, all the subscales were negatively correlated with disease grading (Table 3). Participants with advanced disease had a low quality of life among the sample. For pain (NPRS), we assessed the pain intensity during three activities: Rest, maneuvering stairs and walking. Pain during walking was positively associated with disease grading ( $\tau$ b 0.6111, FDR $2.683 \mathrm{e}^{-15}$ ). Pain during rest ( $\tau \mathrm{b} 0.4981$, FDR1.146e $\mathrm{e}^{-10}$ ) and stair climbing ( $\tau$ b0.5612, FDR4.717 $\mathrm{e}^{-13}$ ) was also positively associated; the calculated associations were statistically significant for pain intensities.

We used a linear regression model to predict the disease grading from the quality-of-life metrics (SF1-SF8); the fitted coefficients are highlighted in Table 3. While all the metrics were significantly correlated with the disease grading in Table 4, only SF1 and SF8 are statistically significant predictors of disease grading for our data among the eight metrics. We also constructed a model using only SF1 and SF8 (Table 5). SF8 shows some statistically significant predictive power among these two variables predictor model when taken with SF1 only. Figures 1 to 5 highlight the association of disease grading with age, WOMAC and QOL.

\section{Discussion}

The study found that patients with a higher disease grading based on KL grade had worse clinical scores, health status and quality of life. Demographic characteristics such as age, weight, height and BMI with disease grading also showed association with disease grading.

The study explores the relationship of disease grading with demographic characteristics and the clinical 


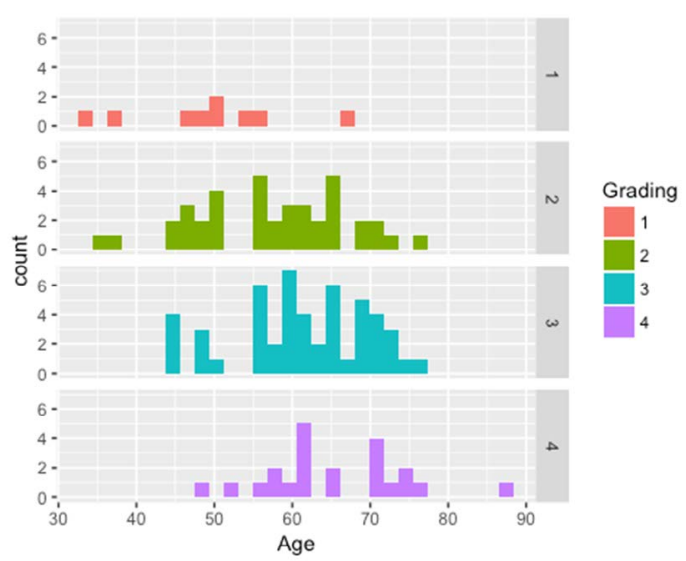

Figure 1. Graphical representation of association of age with disease grading.

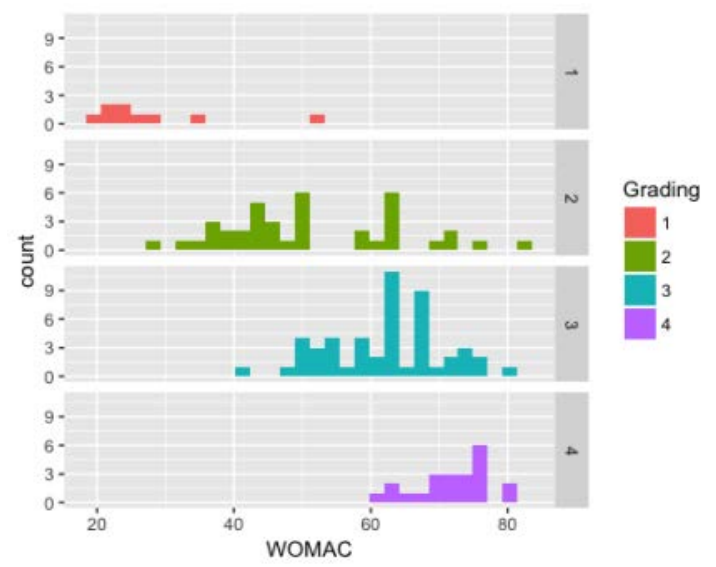

Figure 2. Graphical representation of association of WOMAC scores with disease grading.

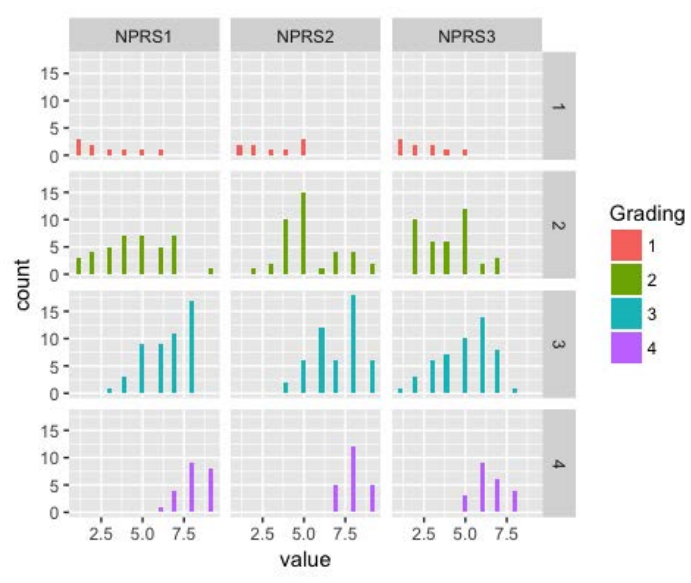

Figure 3. Graphical representation of association of pain intensity with disease grading [NPRS1- pain during walking, NPRS2-pain during stair ascend and descend and NPRS3pain at rest].

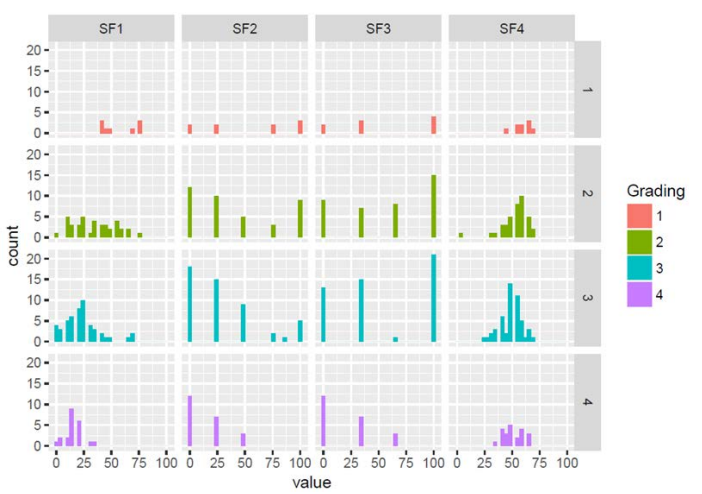

Figure 4. Graphical representation of association of SF subscales with disease grading.

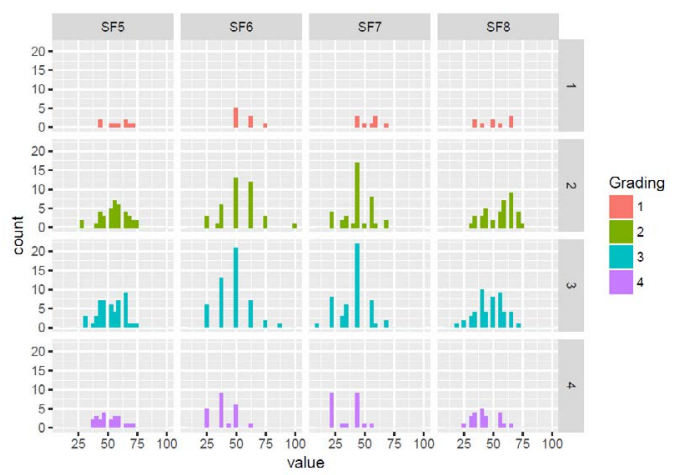

Figure 5. Graphical representation of association of SF subscales with disease grading.

Table 3. Association of disease grading (as measured using Kendall's tau) and its associated p-value for all variables

\begin{tabular}{|l|l|l|l|}
\hline Variables & Kendall's & p-value () & $\begin{array}{l}\text { Corrected p-value } \\
\text { (FDR) }\end{array}$ \\
\hline Age & 0.2852 & $6.335 \mathrm{e}^{-05}$ & 0.0001448 \\
\hline Weight & 0.1176 & 0.09724 & 0.1111 \\
\hline Height & 0.09505 & 0.1845 & 0.1968 \\
\hline BMI & 0.08695 & 0.215 & 0.215 \\
\hline NPRS 1 & $\mathbf{0 . 6 1 1 1}$ & $2.062 \mathrm{e}^{-14}$ & $2.683^{\mathrm{e}-15}$ \\
\hline NPRS2 & 0.5612 & $8.844 \mathrm{e}^{-14}$ & $4.717 \mathrm{e}^{-13}$ \\
\hline NPRS3 & 0.4981 & $2.865 \mathrm{e}^{-11}$ & $1.146 \mathrm{e}^{-10}$ \\
\hline WOMAC & 0.5777 & $3.353 \mathrm{e}^{-11}$ & $2.683 \mathrm{e}^{-15}$ \\
\hline SF1 & -0.4082 & $2.013 \mathrm{e}^{-08}$ & $6.441 \mathrm{e}^{-08}$ \\
\hline SF2 & -0.2364 & 0.002363 & 0.003781 \\
\hline SF3 & -0.2264 & 0.004053 & 0.005895 \\
\hline SF4 & -0.2031 & 0.006119 & 0.008159 \\
\hline SF5 & -0.1634 & 0.0257 & 0.03163 \\
\hline
\end{tabular}




\begin{tabular}{|l|l|l|l|}
\hline SF6 & -0.3209 & $3.362 \mathrm{e}^{-05}$ & $8.964 \mathrm{e}^{-05}$ \\
\hline SF7 & -0.2827 & 0.0002083 & 0.0003704 \\
\hline SF8 & -0.2853 & 0.000106 & 0.0002121 \\
\hline
\end{tabular}

Abbreviations: NPRS1: pain during walking, NPRS2: pain during stair ascend and descend and NPRS3: pain at rest, WOMAC: Western Ontario McMaster Scale, SF1: Physical Functioning, SF2: Role limitations due to physical health, SF3: Role limitations due to emotional problems, SF4: Energy/Fatigue, SF5: Emotional wellbeing, SF6: Social Functioning, SF7: Pain, SF8: General Health.

Table 4. Linear model predicting the disease grading from Quality of Life metrics

\begin{tabular}{|l|l|l|l|l|}
\hline Variables & Estimate & Std. Error & $\mathrm{t}$ value & $\operatorname{Pr}(>|\mathrm{t}|)$ \\
\hline $\mathrm{SF} 1$ & -0.01895 & 0.004572 & -4.145 & $6.678 \mathrm{e}-05$ \\
\hline $\mathrm{SF} 2$ & -0.001059 & 0.002316 & -0.4572 & 0.6484 \\
\hline $\mathrm{SF} 3$ & -0.001136 & 0.001941 & -0.5852 & 0.5596 \\
\hline SF4 & 0.004759 & 0.007759 & 0.6133 & 0.5409 \\
\hline SF5 & 0.002137 & 0.007695 & 0.2777 & 0.7818 \\
\hline SF6 & -0.005188 & 0.005881 & -0.8822 & 0.3796 \\
\hline SF7 & -0.001811 & 0.007092 & -0.2554 & 0.7989 \\
\hline SF8 & -0.01257 & 0.006573 & -1.912 & 0.05848 \\
\hline Intercept & 3.916 & 0.4275 & 9.161 & $3.051 \mathrm{e}-15$ \\
\hline
\end{tabular}

Abbreviations: SF1: Physical Functioning, SF2: Role limitations due to physical health, SF3: Role limitations due to emotional problems, SF4: Energy/Fatigue, SF5: Emotional well-being, SF6: Social Functioning, SF7: Pain, SF8: General Health

Table 5. Linear model predicting the disease grading from only two Quality of Life metrics (SF1 and SF2)

\begin{tabular}{|l|l|l|l|l|}
\hline Variables & Estimate & Std. Error & $\mathrm{t}$ value & $\operatorname{Pr}(>|\mathrm{t}|)$ \\
\hline SF1 & -0.02127 & 0.003516 & -6.048 & $1.804 \mathrm{e}-08$ \\
\hline SF8 & -0.01415 & 0.005369 & -2.635 & 0.009542 \\
\hline Intercept & 4.003 & 0.2645 & 15.13 & $2.569 \mathrm{e}-29$ \\
\hline
\end{tabular}

Abbreviations: SF1: Physical Functioning and SF8: General Health

status of KOA patients. Disease grading was based on anteroposterior weight-bearing X-rays. We used Kendall's tau for finding an association between the desired variables and disease grading. Kendall's tau is a non-parametric measure of strength and direction of the association between two variables. A tau value of +1 means a perfect positive correlation, while -1 means a perfect negative correlation, and 0 denotes no association. In the present study, age, height, weight, BMI, and WOMAC scores showed a positive association with disease grading, while the SF-36 subscales were negatively correlated.

We measured pain intensity using NPRS. Patients were asked to rate their pain during three activities, walking, manipulating stairs and rest. Pain intensity during all three activities was positively correlated with disease grading. Patients with advanced disease reported more pain in our study. Bedson et al. reported a variable relationship of pain with disease grading. In his research, they explained three reasons for this concordance in the literature for this variation. Firstly, X-ray views may affect this relationship. Secondly, the definition of pain used in the study and thirdly, the patient population included being studied ${ }^{28}$. Our findings can be explained in these terms. We assessed pain intensity during three different tasks to gain a comprehensive reporting of pain by the individuals; this may influence our findings.

Moreover, the other factors linking X-ray findings with pain are age and ethnicity ${ }^{28-31}$. The positive association of pain with disease grading may be explained in terms of age and race. It's been reported that young patients do not have significant $\mathrm{x}$-ray changes, and variations in symptoms according to age are reported in the literature ${ }^{28,29}$. In our study, the mean age of the study population was 59.69 years. The older age study population might have resulted in a positive association of reported pain intensity and disease grading. Ethnicity could also be a factor to explain our results. Indian females are found to report more pain than other Asian populations ${ }^{31}$. The current study population comprises old Indian females; this may contribute to the association between disease grading and self-reported pain intensity in the study.

The present study evaluated health status using WOMAC scores. The WOMAC showed a significant positive association with disease grading. Similar findings are reported by Herman et al. In their research, and they demonstrated a probability-order relationship between the clinical and radiographic aspects of knee $\mathrm{OA}^{32}$. Creamer et al. reported that there is no relationship between WOMAC score and disease grading in their study ${ }^{33}$. The difference between their research and our study findings may be attributable to the different statistical assumptions used. Patients in our study were with the more advanced disease tending to have a higher WOMAC rating. 
QOL measured on SF-36 showed a negative association with disease grading. Higher scores on SF-36 indicate better QOL and the lower the score it means lower QOL. The negative association suggests with increasing disease severity, the QOL decreases. SF-36 has several subscales; we calculated associations between all subscales and disease grading. Nikolic et al. demonstrated similar findings using a different questionnaire. They used the EQ-5D questionnaire and concluded that radiographic changes correlate with decreased quality of life ${ }^{17}$ disease severity based on radiography images, functional activity level, and quality of life in patients with knee osteoarthritis in a rural population living in Serbian enclaves in Kosovo, as well as to determine the correlation between the WOMAC and the EQ-5D questionnaire in this population. Method. The cross-sectional study was conducted at the Internal Medicine Clinic, Clinical Hospital Center Pristina-Gracanica, located in Laplje Selo from February to December 2013. One hundred patients with confirmed (American College of Rheumatology criteria. Herman also suggested an association between SF-36 and radiographic grading ${ }^{32}$. However, these studies did not use all the subscales of SF-36. Our study used the RAND scoring system for SF-36 and included all the subscales in the analysis, which is not reported in the literature elsewhere. The ROAD study highlighted that symptomatic KOA is related to lower physical QOL. They said that symptomatic patients report a poor $\mathrm{QOL}^{34}$. The study population in the present study was symptomatic, which could elucidate the findings of our research. We fit a linear regression model to predict disease severity grading from the quality-of-life metrics. The model suggested that SF-Physical Functioning and SF-General health subscales have statistically significant predicting power for predicting disease grading. These findings suggest that patients' physical function and general health may be a predictor of their disease severity. The surprising discovery was that SF-pain could not predict disease grading.

There were various limitations to our study. The sample size used in the study was small; a larger sample size may provide greater statistical power to detect additional predictive factors. We did not control for any confounders. The study did not have male participants, which would have introduced gender bias in the study. Despite limitations, our study had few strengths. This is the first study to our knowledge that used linear regression for predicting disease grading; this may have implications for disease predictions in future studies.
Secondly, patients were recruited from rural populations through camps which may reflect the disease burden's level at grass root levels hence may be more generalizable in the Indian population.

\section{Conclusion}

We conclude that disease grading was associated with pain intensity, health status, and QOL among KOA patients. The study's findings are co relational and future studies may analyze a causal relationship in the studied variable. Our study's other significant finding is that the SF-physical functioning scale and SF-general health scales could predict disease grading using a linear regression model.

\section{Acknowledgement}

Authors would like to thank Dr. Yasir Suhail, PhD (Post Doctorate), University of Connecticut, USA for helping in data analysis.

\section{Conflict of Interest}

The authors declared that they have no competing interests.

\section{References}

1. James SL, Abate D, Abate KH, Abay SM, Abbafati C, Abbasi $\mathrm{N}$ et al. Global, regional and national incidence, prevalence and years lived with disability for 354 diseases and injuries for 195 countries and territories. 1990-2017: A systematic analysis for the Global Burden of Disease Study 2017. Lancet 2018; 392:1789-858. https://doi.org/10.1016/ S0140-6736(18)32279-7

2. Parsons C, Fuggle NR, Edwards MH, Goulston L, Litwic $\mathrm{AE}$, Jagannath $\mathrm{D}$ et al. Concordance between clinical and radiographic evaluations of knee osteoarthritis. Aging Clin Exp Res. 2018; 30:17-25. PMid: 29101670 PMCid: PMC5785611. https://doi.org/10.1007/s40520-017-0847-z

3. Safiri S, Kolahi AA, Smith E, Hill C, Bettampadi D, Mansournia MA et al. Global, regional and national burden of osteoarthritis 1990-2017: A systematic analysis of the Global Burden of Disease Study 2017. Ann Rheum Dis. 2020; annrheumdis-2019-216515. PMid: 32398285. https://doi.org/10.1136/annrheumdis-2019-216515

4. Wood AM, Brock TM, Heil K, Holmes R, Weusten A. A review on the management of Hip and Knee Osteoarthritis. 
Int J Chronic Dis. 2013; 2013:1-10. PMid: 26464847 PMCid: PMC4590943. https://doi.org/10.1155/2013/845015

5. Cui A, Li H, Wang D, Zhong J, Chen Y, Lu H. Global, regional prevalence, incidence and risk factors of Knee Osteoarthritis in population-based studies. E Clinical Medicine. 2020; 29-30: 100587. PMCid: PMC7704420. https://doi.org/10.1016/j.eclinm.2020.100587

6. Kellgren JH LJ. Radiological assessment of osteo-arthrosis. Annals of the Rheumatic Diseases. 1957 Dec; 16(4):494. Ann Rheum Dis. 1957; 16:494. PMid: 13498604 PMCid: PMC1006995. https://doi.org/10.1136/ard.16.4.494

7. Altman R, Asch E, Bloch D, Bole G, Borenstein D, Brandt $\mathrm{K}$ et al. Development of criteria for the classification and reporting of osteoarthritis: Classification of osteoarthritis of the knee. Arthritis Rheum. 1986; 29:1039-49. PMid: 3741515. https://doi.org/10.1002/art.1780290816

8. Zhang W, Doherty M, Peat G, Bierma-Zeinstra SMA, Arden NK, Bresnihan B et al. EULAR evidence-based recommendations for the diagnosis of knee osteoarthritis. Ann Rheum Dis. 2010; 69:483-9. PMid: 19762361. https:// doi.org/10.1136/ard.2009.113100

9. NICE. Overview | Osteoarthritis: care and management | Guidance | NICE. 2021 https://www.nice.org.uk/guidance/ $\operatorname{cg} 177$

10. Wenham CYJ, Grainger AJ, Conaghan PG. The role of imaging modalities in the diagnosis, differential diagnosis and clinical assessment of peripheral joint osteoarthritis. Osteoarthr Cartil. 2014; 22:1692-702. PMid: 25278078. https://doi.org/10.1016/j.joca.2014.06.005

11. Wang X, Oo WM, Linklater JM. What is the role of imaging in the clinical diagnosis of osteoarthritis and disease management? Rheumatol (United Kingdom). 2018; 57: iv51-iv60. PMid: 29351654. https://doi.org/10.1093/rheumatology/ kex501

12. Sinusas K. Osteoarthritis: Diagnosis and treatment. Am Fam Physician. 2012; 85:49-56. https://doi.org/10.1007/ s15200-012-0678-0

13. Bruyère $\mathrm{O}$, Cooper $\mathrm{C}$, Arden $\mathrm{N}$, Branco J, Brandi ML, Herrero-Beaumont $\mathrm{G}$ et al. Can we identify patients with high risk of osteoarthritis progression who will respond to treatment? A Focus on Epidemiology and Phenotype of Osteoarthritis. Drugs and Aging. 2015; 32:179-87. PMid: 25701074 PMCid: PMC4366553. https://doi. org/10.1007/s40266-015-0243-3

14. Bannuru RR, Osani MC, Vaysbrot EE, Arden NK, Bennell $\mathrm{K}$, Bierma-Zeinstra SMA et al. OARSI guidelines for the non-surgical management of knee, hip and polyarticular osteoarthritis. Osteoarthr Cartil. 2019; 27:1578-89. PMid: 31278997. https://doi.org/10.1016/j.joca.2019.06.011

15. Kolasinski SL, Neogi T, Hochberg MC, Oatis C, Guyatt G, Block J et al. 2019 American College of Rheumatology/
Arthritis Foundation Guideline for the Management of Osteoarthritis of the Hand, Hip and Knee. Arthritis Rheumatol. 2020; 72:220-33. PMid: 31908163. https://doi. org/10.1002/art.41142

16. Schmitt J, Lange T, Günther KP, Kopkow C, Rataj E, Apfelbacher C, et al. Indication criteria for total knee arthroplasty in patients with osteoarthritis - A multi-perspective consensus study. Z Orthop Unfall. 2017; 155:539-48. PMid: 29050054. https://doi.org/10.1055/s-0043-115120

17. Nikolic G, Nedeljkovic B, Trajkovic G, Rasic D, Mirkovic Z, Pajovic S et al. Pain, physical function, radiographic features, and quality of life in Knee Osteoarthritis agricultural workers living in rural population. Pain Res Manag. 2019; 2019. PMid: 31662813 PMCid: PMC6791194 https://doi. org/10.1155/2019/7684762

18. Parsons C, Clynes M, Syddall H, Jagannath D, Litwic A, van der Pas $\mathrm{S}$, et al. How well do radiographic, clinical and self-reported diagnoses of Knee Osteoarthritis agree? Findings from the Hertfordshire cohort study. Springerplus .2015; 4. PMid: 25932366 PMCid: PMC4408304. https:// doi.org/10.1186/s40064-015-0949-z

19. World Medical Association. World Medical Association Declaration of Helsinki. JAMA 2013; 310:2191. PMid: 24141714. https://doi.org/10.1001/jama.2013.281053

20. Shirley Ryan Ability Lab. Numeric Pain Rating Scale | Rehab Measures Database. 2021. https://www.sralab.org/ rehabilitation-measures/numeric-pain-rating-

21. McConnell S, Kolopack P, Davis AM. The Western Ontario and McMaster Universities Osteoarthritis Index (WOMAC): A review of its utility and measurement properties. Arthritis Care Res. 2001; 45:453-61. https:// doi.org/10.1002/1529-0131(200110)45:5<453::AIDART365>3.0.CO;2-W

22. Bellamy N, Buchanan WW, Goldsmith $\mathrm{CH}$, Campbell J, Stitt LW. Validation study of WOMAC: A health status instrument for measuring clinically important patient relevant outcomes to antirheumatic drug therapy in patients with osteoarthritis of the hip or knee. J Rheumatol. 1988.

23. Shirley Ryan Ability Lab. Western Ontario and McMaster Universities Osteoarthritis Index | Rehab Measures Database. 2021 Feb. https://www.sralab.org/ rehabilitation-measures/womac-osteoarthritis-index-reliability-validity-and-responsiveness-patients

24. Laucis NC, Hays RD, Bhattacharyya T. Scoring the SF-36 in orthopaedics: A brief guide. J Bone Jt Surg - Am. 2014; 97:1628-34. PMid: 26446970 PMCid: PMC5029523. https://doi.org/10.2106/JBJS.O.00030

25. RAND. 36-Item Short Form Survey (SF-36) Scoring Instructions | RAND. 2021 Feb. https://www.rand.org/ health-care/surveys_tools/mos/36-item-short-form/scoring.html 
26. Benjamini Y, Hochberg Y. Controlling the false discovery rate: A practical and powerful approach to multiple testing. J R Stat Soc Ser B. 1995; 57:289-300. https://doi.org/10.1111/j.2517-6161.1995.tb02031.x

27. Hays RD, Sherbourne CD, Mazel RM. The rand 36-item health survey 1.0. Health Econ. 1993; 2:217-27. PMid: 8275167. https://doi.org/10.1002/hec.4730020305

28. Bedson J, Croft PR. The discordance between clinical and radiographic knee osteoarthritis: A systematic search and summary of the literature. BMC Musculoskelet Disord. 2008; 9:116. PMid: 18764949 PMCid: PMC2542996. https://doi.org/10.1186/1471-2474-9-116

29. Lethbridge-Cejku M, Scott WW, Reichle R, Ettinger WH, Zonderman A, Costa $\mathrm{P}$ et al. Association of radiographic features of osteoarthritis of the knee with knee pain: Data from the baltimore longitudinal study of aging. Arthritis Rheum. 1995; 8:182-8. PMid: 7654803. https://doi.org/10.1002/art.1790080311

30. Cruz-Almeida Y, Sibille KT, Goodin BR, Petrov ME, Bartley EJ, Riley JL et al. Racial and ethnic differences in older adults with knee osteoarthritis. Arthritis Rheumatol.
2014; 66:1800-10. PMid: 24729357 PMCid: PMC4077911. https://doi.org/10.1002/art.38620

31. Chia YC, Beh HC, Ng CJ, Teng CL, Hanafi NS, Choo WY, et al. Ethnic differences in the prevalence of knee pain among adults of a community in a cross-sectional study. BMJ Open. 2016; 6:e011925. PMid: 27909033 PMCid: PMC5168635. https://doi.org/10.1136/bmjopen-2016-011925

32. Herman A, Chechik O, Segal G, Kosashvili Y, Lador R, Salai $\mathrm{M}$, et al. The correlation between radiographic knee $\mathrm{OA}$ and clinical symptoms-do we know everything? Clin Rheumatol. 2015; 34:1955-60. PMid: 25604319. https:// doi.org/10.1007/s10067-015-2871-8

33. Creamer P, Lethbridge-Cejku M, Hochberg MC. Factors associated with functional impairment in symptomatic knee osteoarthritis. Rheumatology. 2000; 39:490-6. PMid: 10852978. https://doi.org/10.1093/rheumatology/39.5.490

34. Muraki S, Akune T, Oka H, En-yo Y, Yoshida M, Saika A, et al. Association of radiographic and symptomatic Knee Osteoarthritis with health-related quality of life in a population-based cohort study in Japan: The ROAD study. Osteoarthr Cartil. 2010; 18:1227-34. PMid: 20633679. https://doi.org/10.1016/j.joca.2010.06.001 